\title{
OXIDATION BEHAVIOR OF STEEL WITH Cr CONTENT AND WATER FLOW RATE
}

Fast water flow facilitates ferrous ion transport leading to flow accelerated corrosion (FAC) of carbon steel and the possibility of a large accident through a failure of a secondary pipe in a nuclear power plant. Ion transport is directly linked to oxide properties such as the thickness, chemical composition and porosity. This work deals with a precise observation of the cross section of the corroded specimen focusing on an oxide passivity and its thickness using SEM (scanning electron microscope) and TEM (transmission electron microscope) as well as an apparent weight loss and a surface observation for the specimens corroded using a rotating cylindrical electrode autoclave system in pure water of $\mathrm{pH} 7$ at $150^{\circ} \mathrm{C}$ having dissolved oxygen below $1 \mathrm{ppb}$ within a flow rate range of 0 to $10 \mathrm{~m} / \mathrm{s}$. The $\mathrm{Cr}$ content in steel was changed from 0.02 to $2.4 \mathrm{wt} \%$. Increasing the $\mathrm{Cr}$ content in the alloy, the FAC rate and oxide thickness decreased. The oxide porosity tends to decrease with the $\mathrm{Cr}$ content and immersion time owing to the development of $\mathrm{Cr}$ containing oxide. The oxidation behavior is not changed with the immersion time.

Keywords: Steel, flow accelerated corrosion, $\mathrm{Cr}$ content, flow rate, surface oxide

\section{Introduction}

Thousands of pipes made of carbon steel are exposed to high temperature, high pressure, and fast flowing water in a nuclear power plant. Ferrous ion tends to dissolve on the steel surface up to equilibrium solubility and transports to bulk water during the operation. A fast water flow facilitates ferrous ion transport leading to flow accelerated corrosion (FAC). FAC can lead to a large accident through a failure of a secondary pipe in a nuclear power plant [1]. Oxide formed on a steel surface can act as a barrier for ferrous ion transport.

Because ion transport is directly linked to the oxide property such as the thickness, chemical composition and porosity, there are numerous studies on the oxidation behavior in an exposed environment [2-6]. Fig. 1 describes the FAC occurring in steel alloy exposed to a flowing solution schematically.

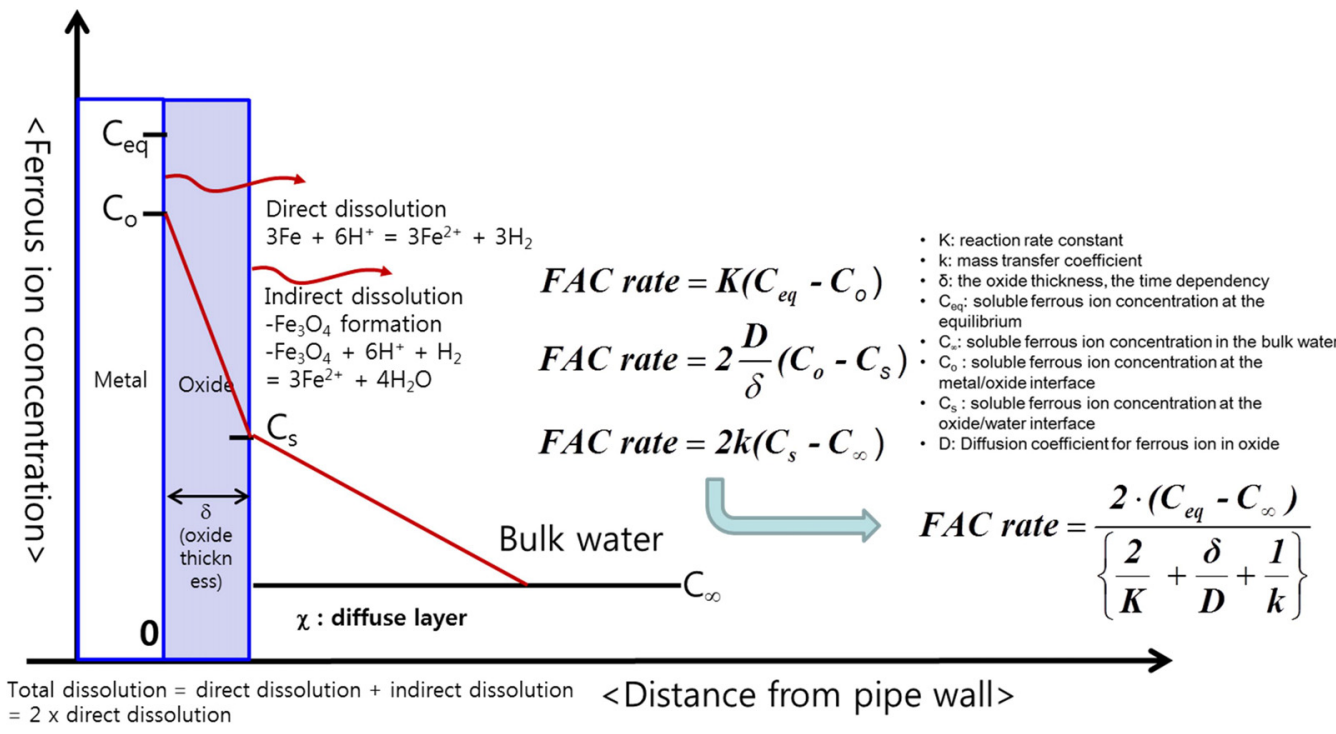

Fig. 1. Schematic diagram of ferrous ion concentration vs. distance from a pipe wall during FAC

* NUCLEAR MATERIALS SAFETY RESEARCH DIVISION, KOREA ATOMIC ENERGY RESEARCH INSTITUTE, DAEDEOK DAERO 989-111, YUSEONG, DAEJEON, KOREA, 34057

\# Corresponding author: djink@kaeri.re.kr 
When oxide is passive, $\mathrm{C}_{\mathrm{o}}, \mathrm{D}$ and $\mathrm{C}_{\mathrm{s}}$ decrease, the concentration gradient in a diffuse layer $(\Delta \mathrm{C} / \mathrm{x})$ decreases, and hence the $\mathrm{FAC}$ rate decreases. In the case of porous oxide, $\mathrm{C}_{\mathrm{o}}$, D and $\mathrm{C}_{\mathrm{s}}$ increase, causing an increase in the concentration gradient in a diffuse layer $(\Delta \mathrm{C} / \mathrm{x})$, and the FAC rate to increase. When increasing the flow rate, the diffuse layer length $(\mathrm{x})$ decreases and the concentration gradient increases in a diffuse layer $(\Delta \mathrm{C} / \mathrm{x})$, leading to an increase in the $\mathrm{FAC}$ rate.

The FAC rate can be formulated in three forms, as shown in Fig. 1, assuming that the total dissolution rate of ferrous ions is composed of a direct dissolution and indirect dissolution, the rates of which are the same [7]. From the FAC rate formulation, it is presumed that the oxide thickness and diffusion coefficient related to oxide porosity is closely related to the FAC phenomena. However, there have been few reports on an oxide investigation based on a TEM analysis, as a function of the $\mathrm{Cr}$ content and flow rate, which are key parameters affecting the FAC.

This work deals with a precise observation of the cross section of the corroded specimen focusing on an oxide passivity and thickness change using SEM (scanning electron microscope) and TEM (transmission electron microscope), as well as an apparent weight loss and a surface observation for the corroded specimens. Oxidation behaviors were investigated in view of the $\mathrm{Cr}$ content in the alloy and flow rate in a pure water of $\mathrm{pH} 7$ at $150^{\circ} \mathrm{C}$ with dissolved oxygen below $1 \mathrm{ppb}$ up to an elapsed time of $4000 \mathrm{~h}$.

\section{Experimental}

The chemical compositions of materials used in this work are shown in Table 1. The Cr content in the alloy was ranged from 0.02 to $2.4 \mathrm{wt} \%$. The specimen geometry was $30 \mathrm{~mm}$ long, $20 \mathrm{~mm}$ wide, and $3 \mathrm{~mm}$ thick. Specimens were cleaned in water, degreased in acetone with an ultrasonic and then dried. The initial weights of the specimens before the experiment were measured.

An FAC test was performed at $150^{\circ} \mathrm{C}$ and at a $\mathrm{pH}$ of 7 for inlet water and flow velocities which were estimated from the angular velocities of a rotating cylinder of $0,2,4$ and $10 \mathrm{~m} / \mathrm{s}$ using a rotating cylindrical specimen, shown in Fig. 2. The test solution is circulated to control the $\mathrm{pH}$ and remove the dissolved ionic species with a flow rate of $50 \mathrm{cc} / \mathrm{min}$ through a test loop equipped with an ion exchanger.

After a high-temperature experiment, the weight of the specimen was measured following ultrasonic cleaning to estimate the corrosion rate and destructive observations using
SEM (scanning electron microscope) and TEM (transmission electron microscope) were performed. The TEM sample used to examine the oxide cross section was prepared using an FIB (focused ion beam).
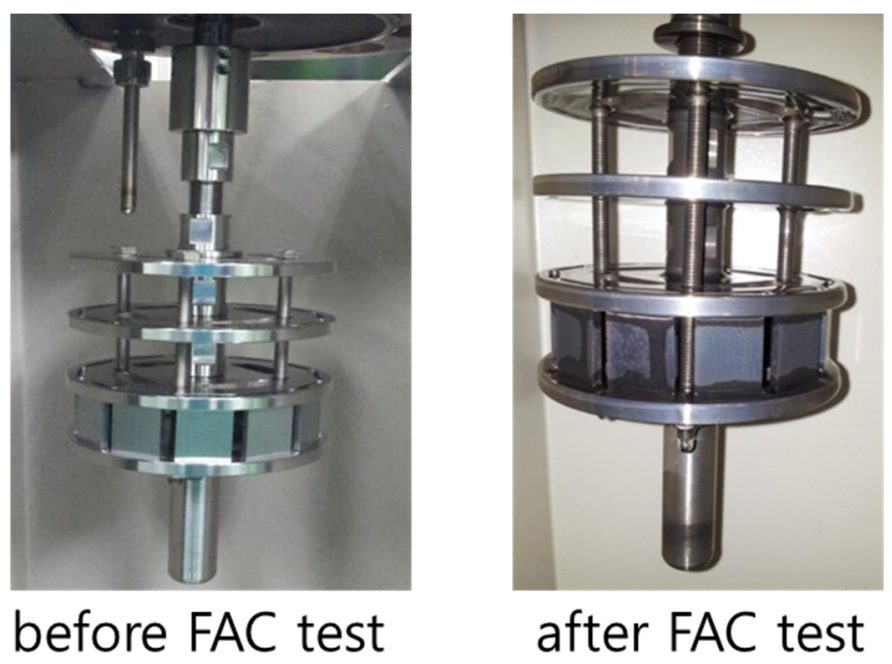

Fig. 2. Rotating cylindrical specimen and holder attached to autoclave for FAC test

\section{Results and discussion}

Fig. 3 shows (a) the FAC rate and (b) an SEM image of a cross section for various materials after 3170 exposure. The FAC rate was obviously decreased with the $\mathrm{Cr}$ content in the alloy. The oxide thickness and roughness were also decreased with the Cr content in the order of SA106, SA487, and A534. Fig. 4 also shows the TEM image of the cross section for various materials after 3170 exposure. In addition to the oxide thickness and roughness based on an SEM image, which can cover a larger area than a TEM image, it is noted that the oxide porosity was decreased with the $\mathrm{Cr}$ content in the alloy. This indicates that the $\mathrm{Cr}$ in the alloy affects the oxide property such as the thickness, roughness and porosity, leading to a decrease in the FAC rate.

Magnetite, $\mathrm{Fe}_{3} \mathrm{O}_{4}$ not containing $\mathrm{Cr}$, which forms on carbon steel under a high-temperature aqueous solution with a low dissolved oxygen is not protective, allowing a continuous dissolution of ferrous ion and hence a high FAC rate and oxide thickness. The local roughness is also increased, caused by active FAC as shown in Fig. 3b. However, when the $\mathrm{Cr}$ content is increased in the alloy, $\mathrm{Cr}$ is incorporated into the oxide, enhancing the oxide passivity and decreasing the FAC rate and roughness. It is

TABLE 1

Chemical composition of specimens

\begin{tabular}{|c|c|c|c|c|c|c|c|c|c|c|c|}
\hline \hline Material & $\mathrm{Cr}$ & $\mathrm{Mo}$ & $\mathrm{V}$ & $\mathrm{Cu}$ & $\mathrm{Mn}$ & $\mathrm{Ni}$ & $\mathrm{Si}$ & $\mathrm{Ti}$ & $\mathrm{C}$ & $\mathrm{P}$ & $\mathrm{S}$ \\
\hline A106 Gr.B & 0.02 & 0.01 & & 0.04 & 0.37 & 0.02 & 0.22 & & 0.19 & 0.008 & 0.006 \\
\hline A508 Gr.3 & 0.17 & 0.46 & 0.001 & 0.03 & 1.22 & 0.68 & 0.21 & 0.002 & 0.22 & 0.007 & 0.002 \\
\hline A534 8620H & 0.47 & $0.15 \sim 0.30$ & & $\mathrm{Max} 0.3$ & $0.6 \sim 0.9$ & $0.4 \sim 0.7$ & $0.15 \sim 0.35$ & & $0.17 \sim 0.23$ & $\mathrm{Max} 0.03$ & $\mathrm{Max} 0.03$ \\
\hline A508 Gr.4N & 1.80 & 0.49 & 0.003 & 0.001 & 0.33 & 3.44 & 0.21 & 0.006 & 0.18 & 0.0029 & 0.0019 \\
\hline A336 F22V & 2.40 & 0.9 & 0.25 & 0.1 & 0.4 & 0.1 & 0.1 & 0.01 & 0.10 & 0.006 & 0.001 \\
\hline
\end{tabular}




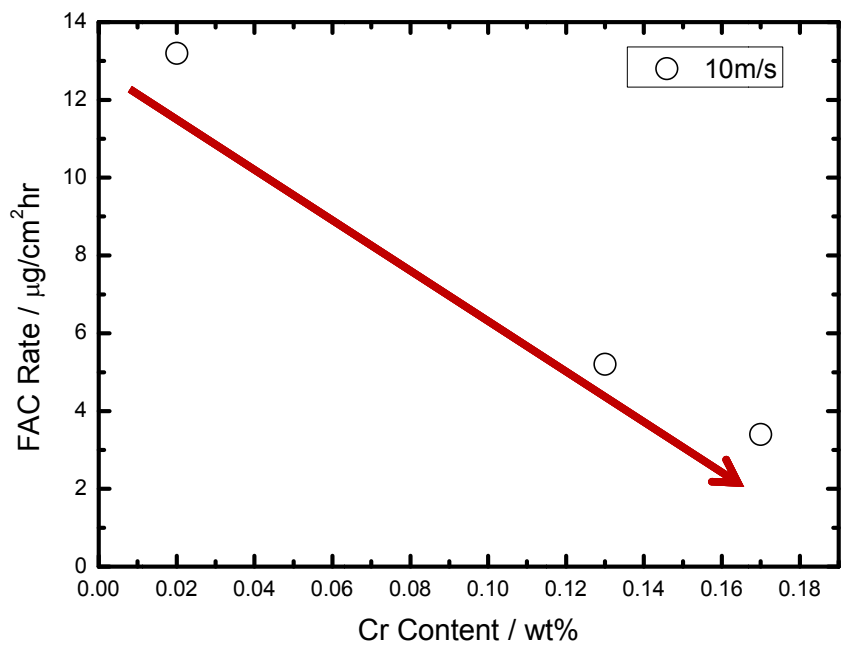

(a)
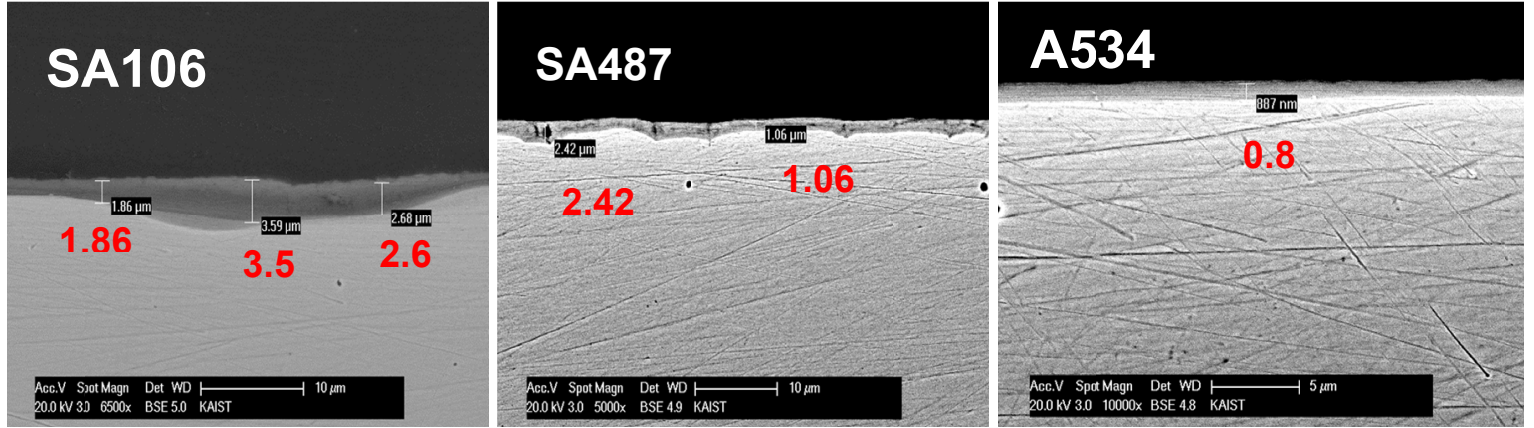

(b)

Fig. 3. (a) FAC rate and (b) SEM images of cross section for various materials after 3170 exposure
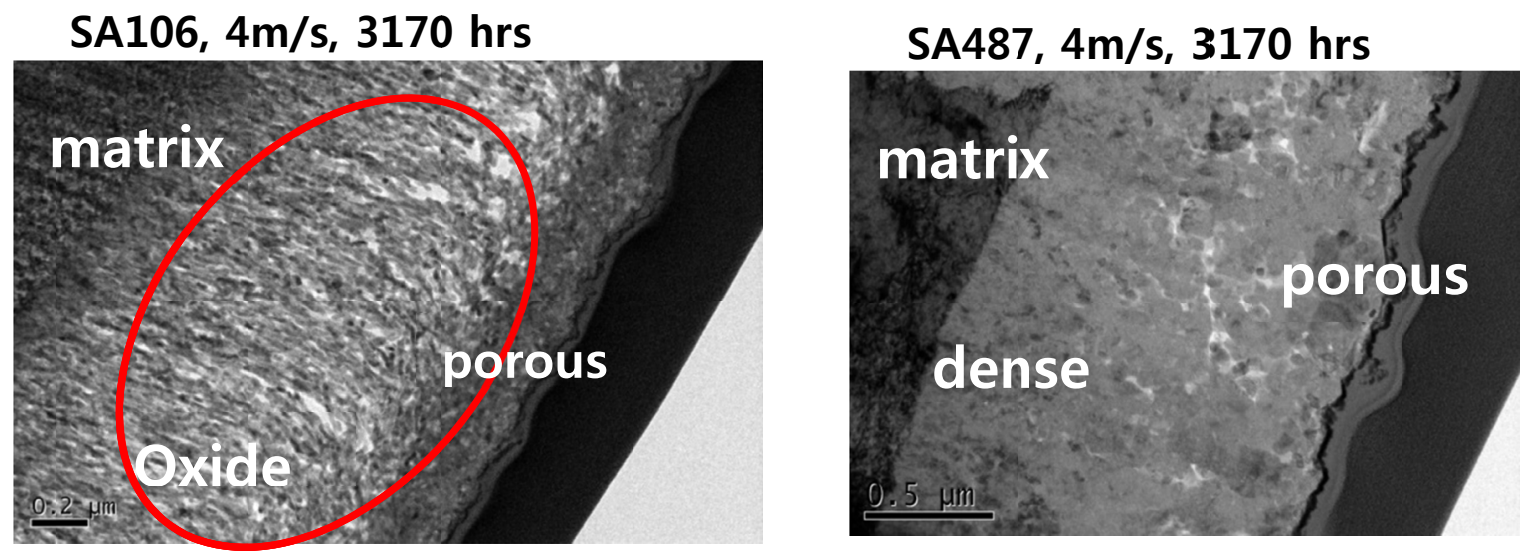

A534, 4m/s, $3170 \mathrm{hrs}$

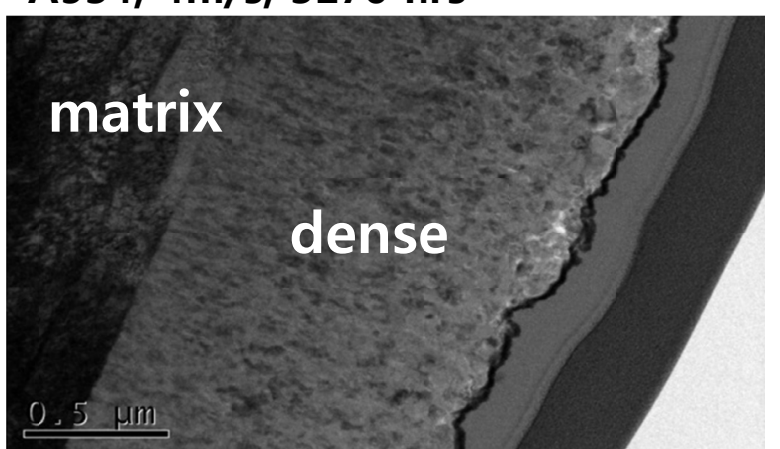

Fig. 4. TEM images of cross section for various materials after 3170 exposure 
known [2,3] that Cr oxide is more passive than Fe oxide, and its application as corrosion resistant treatment such as stainless steel is widely used. It was also reported [8] that the $\mathrm{Cr}$ is enriched in the oxide over time because the Cr solubility is lower than that of the $\mathrm{Fe}$ in the solution.

Table 2 shows the relative oxide porosity defined as the ratio of corrosion rate (= corrosion rate of interesting alloy / corrosion rate of carbon steel (SA106)), assuming that the oxide formed on carbon steel (SA106) is perfectly porous. Similarly, the relative oxide passivity can be defined as relative oxide porosity subtracted from unity.

$$
\text { Relative oxide porosity }=\frac{\text { corrosion rate of an alloy }}{\text { corrosion rate of } S A 106}
$$

From Table 2, SA508 containing $\mathrm{Cr}$ of $0.17 \mathrm{wt} \%$ shows a better passivity than SA487 containing $\mathrm{Cr}$ of $0.13 \mathrm{wt} \%$. The oxide passivity was improved with the exposure time, which may be attributed to an enrichment of $\mathrm{Cr}$ in the oxide. The $\mathrm{Cr}$ can be enriched on surface with the immersion time due to solubility difference between $\mathrm{Fe}$ and $\mathrm{Cr}$ leaving more passive oxide on the surface.

TABLE 2

Relative oxide porosity for SA487 and SA508 as a function of the exposure time

\begin{tabular}{|c|c|c|c|c|c|}
\hline \hline $\begin{array}{c}\text { Exposure } \\
\text { time (hr) }\end{array}$ & $\mathbf{8 4 0}$ & $\mathbf{1 6 7 0}$ & $\mathbf{2 5 1 0}$ & $\mathbf{2 9 3 0}$ & Remark \\
\hline SA487 & 0.3 & 0.2 & 0.2 & 0.2 & Time dependency \\
\hline SA508 & 0.2 & 0.1 & 0.1 & 0.1 & Better passivity \\
\hline
\end{tabular}

Fig. 5 shows the FAC rate with the flow rate for SA106. When the flow rate increases, the diffuse layer length is decreased, leading to a concentration gradient increase in the diffuse length and thus an FAC rate increase. It was reported [9] that the diffuse layer length is decreased from 0.5 to $0.01 \mathrm{~mm}$ when solution is stirred.

Fig. 6 shows the surface appearance with a flow rate for SA106 after $1670 \mathrm{~h}$ of exposure. A pit like morphology was seen and developed with a flow rate in view of the number of pits. It was shown that a pit like morphology is caused by the inclusion dissolution at the early stage, and is developed into

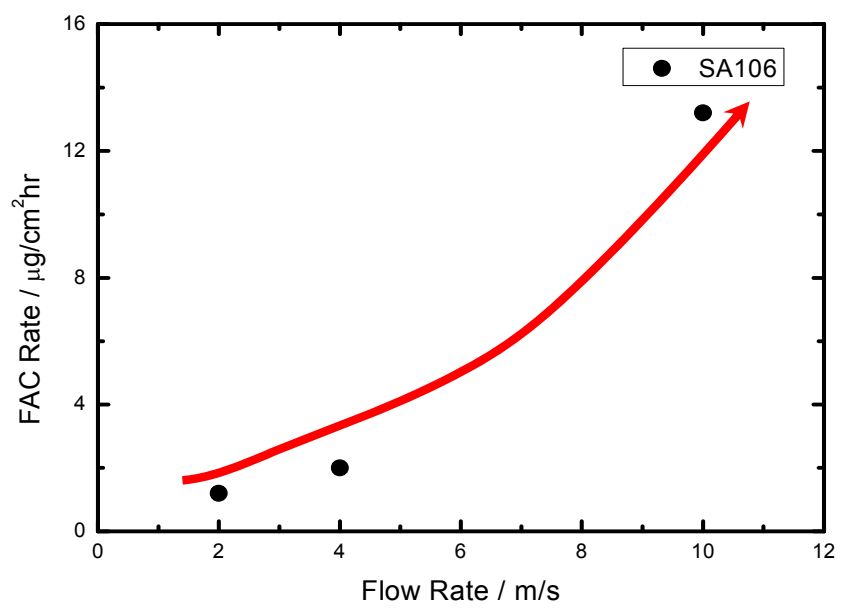

Fig. 5. FAC rate as a function of the flow rate for SA106

a scallop (orange peel) pattern [10]. From this, it is presumed that the density and size of a pit like morphology is an index of the FAC rate.

Fig. 7 shows a TEM image of the cross section of SA106 after $1670 \mathrm{~h}$ of exposure. The oxide thickness was decreased with the flow rate. It seems that the oxide porosity is not changed with the flow rate, as shown in a TEM image. The FAC rate is increased and the oxide thickness is decreased, which is caused by the relative ease of the mass transfer at a relatively higher flow rate, while the FAC rate and oxide thickness are decreased with the $\mathrm{Cr}$ content in the alloy.

Table 3 shows the corrosion rate ratio defined as the ratio of corrosion rate (= corrosion rate at low flow rate / corrosion rate at high flow rate $(10 \mathrm{~m} / \mathrm{s})$ for SA106) with the exposure time.

\section{$\underset{(\text { flow rate })}{\text { Corrosion rate ratio }}=\frac{\text { corrosion rate at low flow rate }}{\text { corrosion rate at high flow rate }}$}

From Table 3, the corrosion rate ratio is not sensitive to the elapsed time of this work indicating that the corrosion kinetics is not changed with the time. From the results of Fig. 7 and Table 3, it seems that the FAC rate with the flow rate does not depend on the oxide formation kinetics but depends only on the mass transfer. Consequently, this leads to an insensitivity of oxide porosity with the flow rate, as shown in Fig. 7.
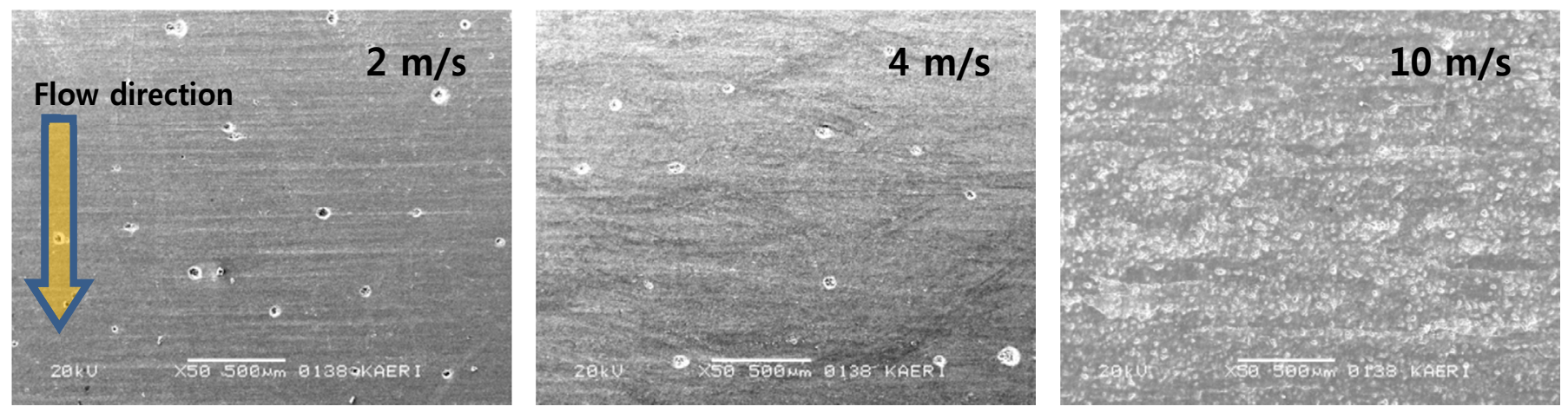

Fig. 6. Surface appearance with the flow rate for SA106 after $1670 \mathrm{~h}$ of exposure 


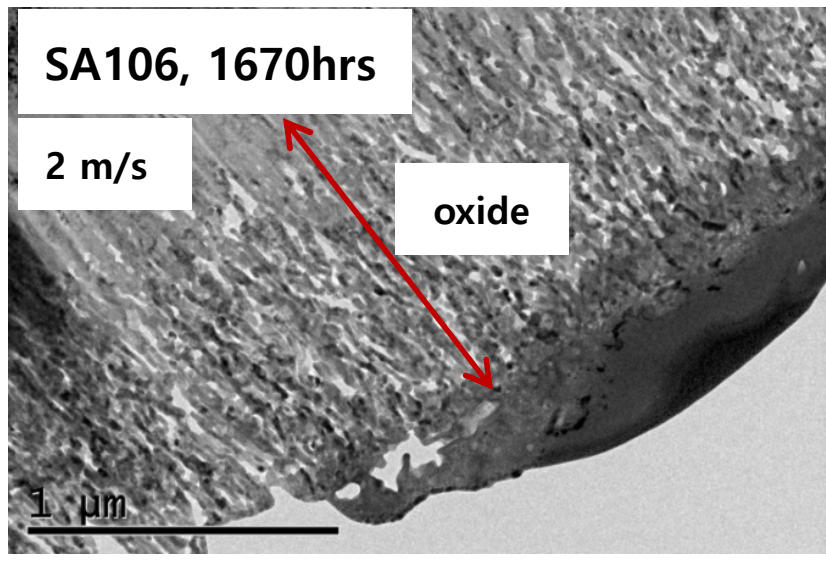

Fig. 7. TEM image of cross section for SA106 after $1670 \mathrm{~h}$ of exposure

TABLE 3

Corrosion rate ratio for SA106 as a function of the exposure time

\begin{tabular}{|c|c|c|c|c|c|}
\hline $\begin{array}{c}\text { Elapsed } \\
\text { time (hrs) }\end{array}$ & $\mathbf{4 1 0}$ & $\mathbf{1 6 7 0}$ & $\mathbf{2 0 9 0}$ & $\mathbf{2 9 3 0}$ & Remark \\
\hline $4 \mathrm{~m} / \mathrm{s}$ & 0.15 & 0.15 & 0.15 & 0.14 & $\begin{array}{c}\text { Insensitive to } \\
\text { immersion time }\end{array}$ \\
\hline $2 \mathrm{~m} / \mathrm{s}$ & 0.11 & 0.09 & 0.09 & 0.08 & immention \\
\hline
\end{tabular}

\section{Conclusions}

1. The FAC rate, oxide thickness and oxide porosity decreased with the Cr content in an alloy. The passivity is improved with the elapsed time owing to the development of $\mathrm{Cr}$ containing oxide.

2. The FAC rate was increased but the oxide thickness was decreased with the flow rate, while the oxide porosity is almost unchanged. The corrosion kinetics does not seem to be changed with the elapsed time. The pit density was increased with the flow rate based on the surface appearance.

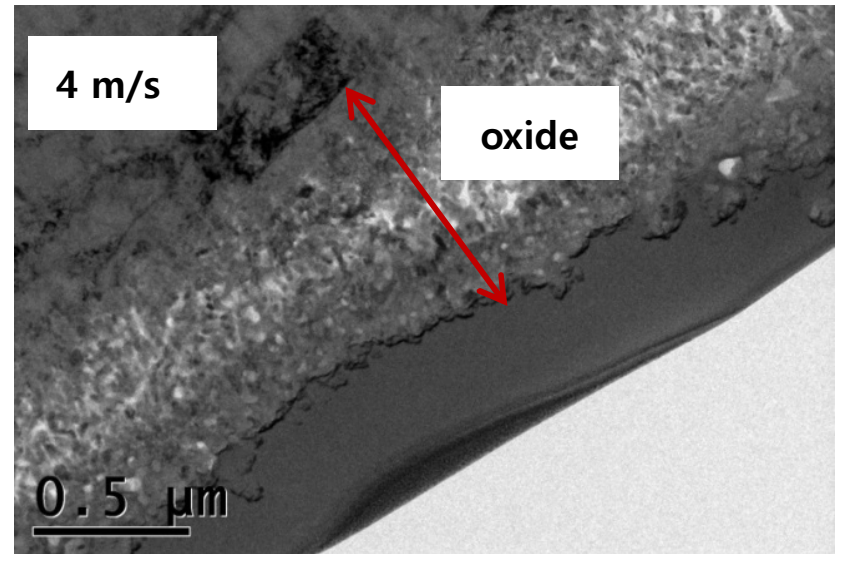

Acknowledgments

This work was financially supported by the Ministry of Science, ICT and Future Planning (MSIP) of Korea.

\section{REFERENCES}

[1] Flow accelerated corrosion in power plants, EPRI report, TR-106611-R1, Palo Alto, CA, 1998.

[2] J. Robertson, Corrosion Science 29, 1275 (1989).

[3] D.J. Kim, H.C. Kwon, H.P. Kim, Corrosion Science 50, 1221 (2008).

[4] D.J. Kim, H.C. Kwon, H.W. Kim, S.S. Hwang, H.P. Kim, Corrosion Science 53, 1247 (2011).

[5] S.Y. Kang, D.W. Lee, J. Korean Power Metallurgy Institute, 21, 260 (2014).

[6] J.-P. Lee, J.-H. Hong, D.-K. Park, I.-S. Ahn, J. Korean Power Metallurgy Institute, 22, 52 (2015).

[7] L.E. Sanchez-Caldera, P. Griffith, E. Rabinowicz, J. Engineering for Gas Turbines and Power 110, 180 (1988).

[8] H. Abe, T. Yano, Y. Watanabe, M. Nakashima, T. Tatsuki, presented at FAC 2016, May 24-27, 2016, Lille, France.

[9] S.I. Pyun, The Fundamentals of Corrosion of Metals and Their Application into Practice, Chungwoongak 2006.

[10] H.P. Kim, M.J. Kim, D.J. Kim, presented at $19^{\text {th }}$ ICC, Nov. 2-6, 2014, Jeju, Korea. 